\title{
ZOO CARDS - O SUPER TRUNFO ANIMAL: UM JOGO DIDÁTICO COMO FERRAMENTA PARA O ENSINO NO ZOOLÓGICO
}

\author{
Jéssyca Danieli Barros ${ }^{1}$ \\ Sílvia Maria de Campos Machado Ortolano² \\ Ricardo Toshio Fujihara ${ }^{3}$
}

Resumo: Os zoológicos conectam as pessoas com a natureza e são vitais para a construção do apoio à preservação. O emprego de atividades interativas, como os jogos didáticos, pode ser uma importante ferramenta para a Educação Ambiental praticada nesses espaços. Sendo assim, este trabalho desenvolveu um jogo didático baseado no jogo de cartas Super Trunfo ${ }^{\circledR}$. Este pode servir como importante ferramenta para o aprendizado sobre as espécies animais presentes no Parque Ecológico de Americana, SP, além de promover o desenvolvimento da consciência ambiental. Configura-se ainda, como um recurso didático para as aulas de Ciências ${ }^{4}$.

Palavras-chave: Parque Ecológico de Americana; Lúdico; EnsinoAprendizagem; Educação Ambiental; Preservação.

\footnotetext{
1 Universidade Federal de São Carlos, CCA/UFSCar. E-mail: jessycaabarros@gmail.com

2 Parque Ecológico Municipal de Americana "Eng. Cid Almeida Franco". E-mail: pema@americana.sp.gov.br

${ }^{3}$ Universidade Federal de São Carlos, CCA/UFSCar. E-mail: rtfujihara@ufscar.br

${ }^{4}$ O jogo "Zoo Cards" está disponível gratuitamente para download e impressão no endereço: https://drive.ufscar.br/d/9508fe1c55/.
} 


\section{Introdução}

A partir da Revolução Industrial desencadearam-se grandes prejuízos aos ecossistemas, resultantes da exploração e destruição desordenada do meio ambiente (CMMAD, 1991). A constante evolução da produção e os avanços tecnológicos conduziram o homem a patamares elevados de conforto, praticidade e rapidez, baseados, contudo, em desenvolvimentos inconscientes acerca do caráter finito dos recursos naturais do planeta (TORRES; BALASSIANO, 2010). Em virtude disso, a questão ambiental está cada vez mais presente em nosso cotidiano, principalmente no que tange à preservação da qualidade de vida.

Trevisol (2003) propõe que a Educação Ambiental (EA) seja capaz de levar os indivíduos a uma mudança de hábitos, almejando uma relação mais sustentável com o meio em que estão inseridos. Uma estratégia-chave para alavancar a revolução necessária nas atitudes e comportamentos, é reconectar o público com a natureza. As pessoas devem compreender que a vida na Terra deve ser preservada, pois as espécies dependem uma das outras, e a própria sobrevivência humana depende de um ecossistema em equilíbrio (BARONGI et al., 2015).

Partindo desse pressuposto, os zoológicos podem contribuir para a conservação do meio ambiente (WAZA, 2017), pois além de servirem para atividades de lazer, também são locais de estudo, pesquisa e conservação ex situ (TELLES et al., 2002; ARAGÃO; KAZAMA, 2013). A criação da Sociedade de Zoológicos do Brasil (SZB) possibilitou o desenvolvimento de projetos em prol dessas instituições e, acompanhando tal evolução, a EA passou a fazer parte dos objetivos dos zoológicos, trabalhando maneiras de educar a partir da vivência e do contato com os animais silvestres, atraindo um elevado número de visitantes que ficam encantados e inspirados por esses encontros com a natureza (MERGULHÃO; VASAKI, 2002; BARONGI et al., 2015).

No entanto, ao se trabalhar a EA sob uma perspectiva formal, é importante buscar práticas pedagógicas que motivem o interesse dos alunos, fazendo com que haja uma interação no processo de ensino-aprendizagem, ou seja, que os conceitos ambientais sejam desenvolvidos de forma atrativa, por meio de atividades lúdicas (REIGOTA; SANTOS, 2005). Neste sentido, uma alternativa de unificar o ambiente dos zoológicos e do ensino é o desenvolvimento de jogos didáticos como ferramenta de aprendizagem, que pode ser um instrumento pedagógico que conduz o tutor à condição de orientador, estimulador e avaliador deste processo (CUNHA, 1998; ZANON; GUERREIRO; OLIVEIRA, 2008). O jogo didático possui duas funções principais que devem estar em constante equilíbrio: a primeira diz respeito à função lúdica, que está ligada à diversão, ao prazer e até o desprazer, e a segunda, atrelada à função educativa, que objetiva a ampliação dos conhecimentos dos educandos (GODOY; OLIVEIRA; CODOGNOTO, 2010). Assim, é interessante que os zoológicos busquem alternativas que possibilitem atividades lúdicas e experiências mais interativas. 
Um zoológico muito conhecido na região metropolitana de Campinas, e que apresenta perspectivas de trabalhos e projetos de EA, é o Parque Ecológico Municipal de Americana "Engenheiro Cid Almeida Franco" (aqui abreviado como PEMA). Foi inaugurado em 12 de outubro de 1984, e é subsidiado pela Prefeitura Municipal de Americana, SP. Possui uma área total de $120 \mathrm{mil} \mathrm{m}^{2}$, com um plantel de aproximadamente 400 animais, entre répteis, aves e mamíferos de mais de 100 espécies, dos quais $80 \%$ pertencem à fauna brasileira e várias estão ameaçadas de extinção, o que mostra a preocupação com o estudo e a conservação desses animais. Os programas de EA no PEMA são desenvolvidos com crianças, jovens, professores e a comunidade em geral. Para isso, apresentam uma estrutura denominada Núcleo de Educação Ambiental (NEA), inaugurada em 05 de junho de 1997, onde são realizados trabalhos educacionais (visitas monitoradas, palestras, cursos de férias, oficinas etc.), especialmente com escolas do ensino fundamental que visitam o local durante $o$ ano todo.

Neste contexto, o presente trabalho teve como objetivo desenvolver um jogo didático baseado no jogo de cartas Super Trunfo ${ }^{\circledR}$. Este pode servir como importante ferramenta para 0 aprendizado sobre as espécies animais presentes no Parque Ecológico de Americana, SP, além de promover o desenvolvimento da consciência ambiental.

\section{Material e Métodos}

\section{Levantamento das espécies e obtenção das imagens}

Inicialmente foi realizado um levantamento para a seleção das espécies a serem utilizadas no jogo. Do total de 400 animais presentes no PEMA, 32 foram escolhidos, com base nos seguintes critérios: i) grau de ameaça de extinção; ii) se os animais são exóticos; e iii) espécies que não possuem características de conhecimento do público em geral (Tabela 1, próxima página).

Após esta etapa, foram realizadas visitas periódicas aos recintos para a observação dos animais em cativeiro e obtenção de fotografias. $O$ acesso contou com o apoio da equipe técnica do PEMA, composta por biólogos e veterinários.

\section{Desenvolvimento do jogo "Zoo Cards - O Super Trunfo Animal"}

O jogo "Zoo Cards - O Super Trunfo Animal" foi baseado no Super Trunfo ${ }^{\circledR}$, um conjunto de cartas colecionáveis distribuído no Brasil pela Grow Jogos e Brinquedos Ltda ${ }^{\circledR}$, além do jogo A Mata é o Bicho ${ }^{\circledR}$, desenvolvido pela Fundação SOS Mata Atlântica ${ }^{\circledR}$. Em ambos, o objetivo é tomar as cartas dos outros participantes por meio da seleção de características de cada carta (como por exemplo, velocidade, altura e longevidade). O jogo comporta de dois a oito participantes e possui classificação livre, podendo ser disputado por qualquer pessoa alfabetizada.

revista brasileira educação ambiental 
Tabela 1: Lista dos animais do PEMA selecionados para o jogo.

\begin{tabular}{|c|c|c|c|}
\hline Nome popular & Nome científico & Classe & Grau de extinção* \\
\hline Arara-azul & Anodorhynchus hyacinthinus & Aves & Ameaçado (Vulnerável - CITES I) \\
\hline Arara-da-testa-vermelha & Ara rubrogenys & Aves & Ameaçado (Em perigo - CITES I) \\
\hline Ararajuba & Guaruba guarouba & Aves & Ameaçado (Vulnerável - CITES I) \\
\hline Ema & Rhea americana & Aves & - \\
\hline Harpia & Harpia harpyja & Aves & Ameaçado (Vulnerável - CITES I) \\
\hline Mutum-do-sudeste & Crax blumenbachii & Aves & Ameaçado (Vulnerável - CITES I) \\
\hline Papagaio-da-cara-roxa & Amazona brasiliensis & Aves & Ameaçado (Vulnerável - CITES I) \\
\hline Papagaio-do-peito-roxo & Amazona vinacea & Aves & Ameaçado (Vulnerável - CITES I) \\
\hline Tucano-toco & Ramphastos toco & Aves & - \\
\hline Urubu-rei & Sarcoramphus papa & Aves & - \\
\hline Anta & Tapirus terrestris & Mammalia & - \\
\hline Aoudad & Ammotragus lervia & Mammalia & Ameaçada (Vulnerável - CITES II) \\
\hline Cachorro-vinagre & Speothos venaticus & Mammalia & Ameaçado (Vulnerável - CITES I) \\
\hline Furão & Galictis cuja & Mammalia & - \\
\hline Gato-do-mato-pequeno & Leopardus guttulus & Mammalia & Ameaçado (Vulnerável - CITES I) \\
\hline Gato-maracajá & Leopardus wiedii & Mammalia & Ameaçado (Vulnerável - CITES I) \\
\hline Hipopótamo & Hippopotamus amphibius & Mammalia & - \\
\hline Jaguatirica & Leopardus pardalis & Mammalia & Ameaçado (Vulnerável - CITES I) \\
\hline Leão & Panthera leo & Mammalia & - \\
\hline Lobo-guará & Chrysocyon brachyurus & Mammalia & Ameaçado (Vulnerável - CITES II) \\
\hline Macaco-aranha-de-testa-branca & Ateles marginatus & Mammalia & Ameaçado (Em perigo - CITES II) \\
\hline Macaco-prego-do-peito-amarelo & Sapajus xanthosternos & Mammalia & Ameaçado (Criticamente - CITES II) \\
\hline Mão-pelada & Procyon cancrivorus & Mammalia & - \\
\hline Mico-leão-da-cara-dourada & Leontopithecus chrysomelas & Mammalia & Ameaçado (Em perigo - CITES I) \\
\hline Onça-pintada & Panthera onca & Mammalia & Ameaçada (Vulnerável - CITES I) \\
\hline Quati & Nasua nasua & Mammalia & - \\
\hline Sagui-preto-de-mão-dourada & Saguinus midas & Mammalia & - \\
\hline Tamanduá-bandeira & Myrmecophaga tridactyla & Mammalia & Ameaçado (Vulnerável - CITES II) \\
\hline Tigre-siberiano & Panthera tigris altaica & Mammalia & Ameaçado (Em perigo - CITES I) \\
\hline Jacaré-do-papo-amarelo & Caiman latirostris & Reptilia & - \\
\hline Jiboia & Boa constrictor & Reptilia & - \\
\hline Sucuri & Eunectes murinus & Reptilia & - \\
\hline
\end{tabular}

Fonte: BAILLIE; HILTON-TAYLOR; STUART (2004).

O levantamento bibliográfico sobre as espécies (classificação taxonômica; dados bioecológicos; grau de risco de extinção; tráfico ilegal; curiosidades em geral) foi realizado a partir de Baillie, Hilton-Taylor e Stuart (2004), Frisch e Frisch (2005), Machado, Drummond e Paglia (2008), Forshaw

Revbea, São Paulo, V. 13, № 4: 145-155, 2018. 
(2010) e ICMBIO (2014). Estas informações foram padronizadas e utilizadas na elaboração das cartas do jogo.

Todos os valores adotados no jogo "Zoo Cards" são dados gerais que podem variar de acordo com as condições abióticas, principalmente entre aves, répteis e mamíferos. Além disso, são pouco conhecidos pela população, principalmente por crianças e adolescentes:

Peso: é uma relação que pode variar muito entre os animais, inclusive em indivíduos da mesma espécie. Os hábitos podem influenciar diretamente nesse parâmetro, como o dormitório, disponibilidade de alimento, local em que o animal vive, fatores ambientais, genéticos etc. Desta forma, valores médios das espécies do plantel foram calculados e adicionados às cartas.

Desenvolvimento: os animais apresentam grande diversidade de desenvolvimento. Existem aqueles que se desenvolvem durante um período menor de tempo e outros em um maior, e isso dependerá das características de cada espécie. Em aves e répteis têm-se o período de incubação dos ovos, já nos mamíferos ocorre pela gestação.

Ninhada: é definida pelo total de filhotes que a fêmea é capaz de gerar de uma só vez. Esse dado está representado no jogo pelo valor médio de cada espécie, pois em alguns casos pode haver variação. Espécies pertencentes ao mesmo gênero podem variar consideravelmente, $e$ isso se deve a fatores como habitat, saúde, alimentação, pressão predatória etc.

Longevidade: na maioria dos animais, a longevidade está relacionada ao tamanho do corpo e à idade de maturação sexual (embora existam casos que fujam a essa regra). Generalizando, podemos dizer que vertebrados maiores vivem mais do que vertebrados menores. Animais com metabolismo muito acelerado (por exemplo, roedores) vivem menos que animais com metabolismo lento (por exemplo, tartarugas).

Ameaça de extinção: dezenove espécies do PEMA presentes no jogo sofrem risco de extinção, principalmente as endêmicas.

\section{Resultados e discussão}

\section{Descrição geral do jogo "Zoo Cards - O Super Trunfo Animal"}

O jogo "Zoo Cards" conta com um conjunto de 32 cartas $(8,0 \times 5,0$ $\mathrm{cm}$ ) e um manual de instruções (Figura 1). Em cada uma delas é apresentado o animal e sua respectiva foto, e logo abaixo, o nome popular, o nome científico, suas características (peso, desenvolvimento, ninhada e longevidade), além de curiosidades gerais. Nos animais ameaçados de extinção há um ícone junto à foto. Cada carta é indicada por um código no canto superior esquerdo (A1 a $\mathrm{A} 4 \ldots \mathrm{H} 1$ a $\mathrm{H} 4)$, totalizando oito grupos (Figura 2). 


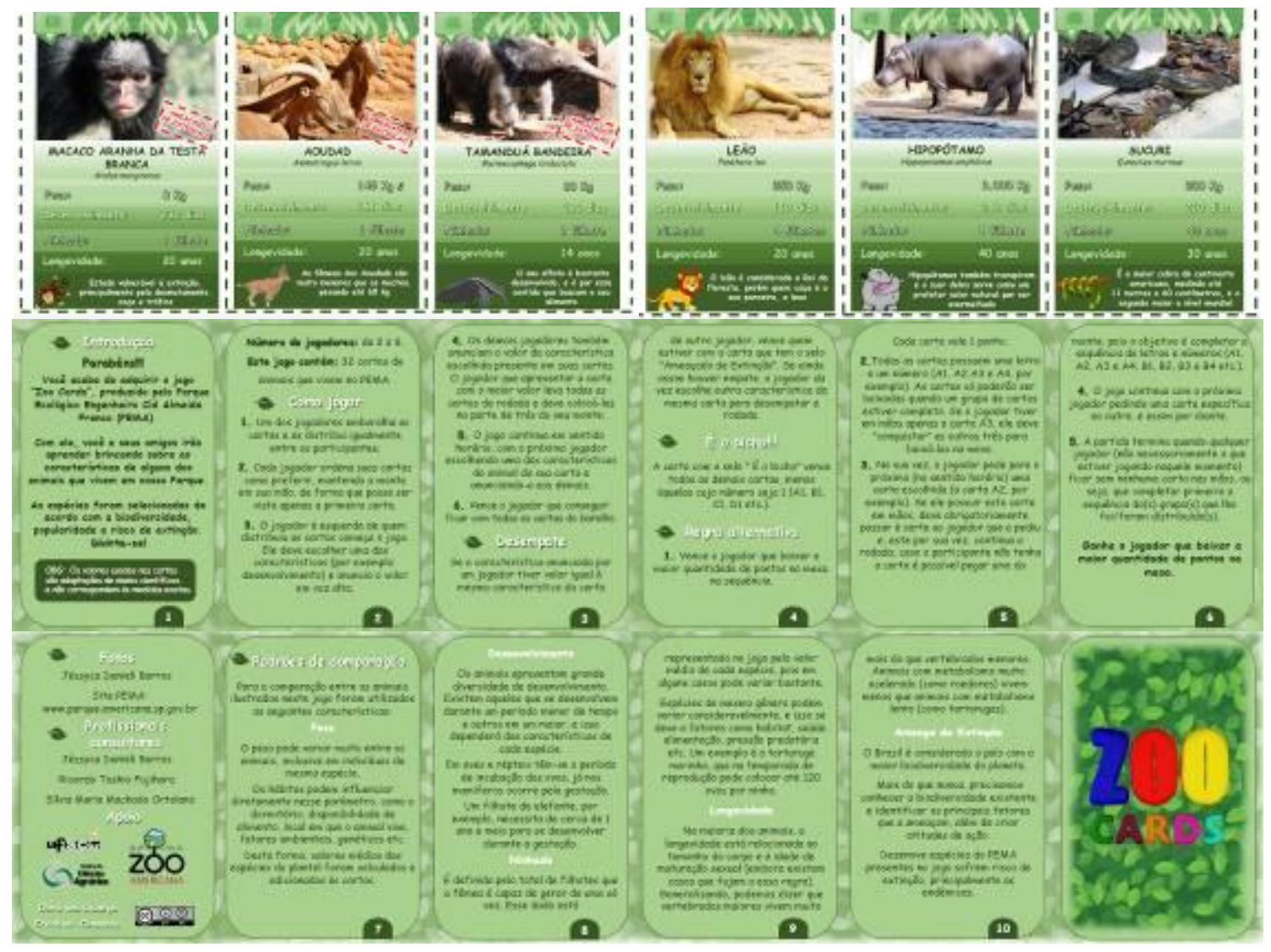

Figura 1: Exemplos de cartas e manual de instruções do jogo "Zoo Cards". Fonte: Autoria própria.

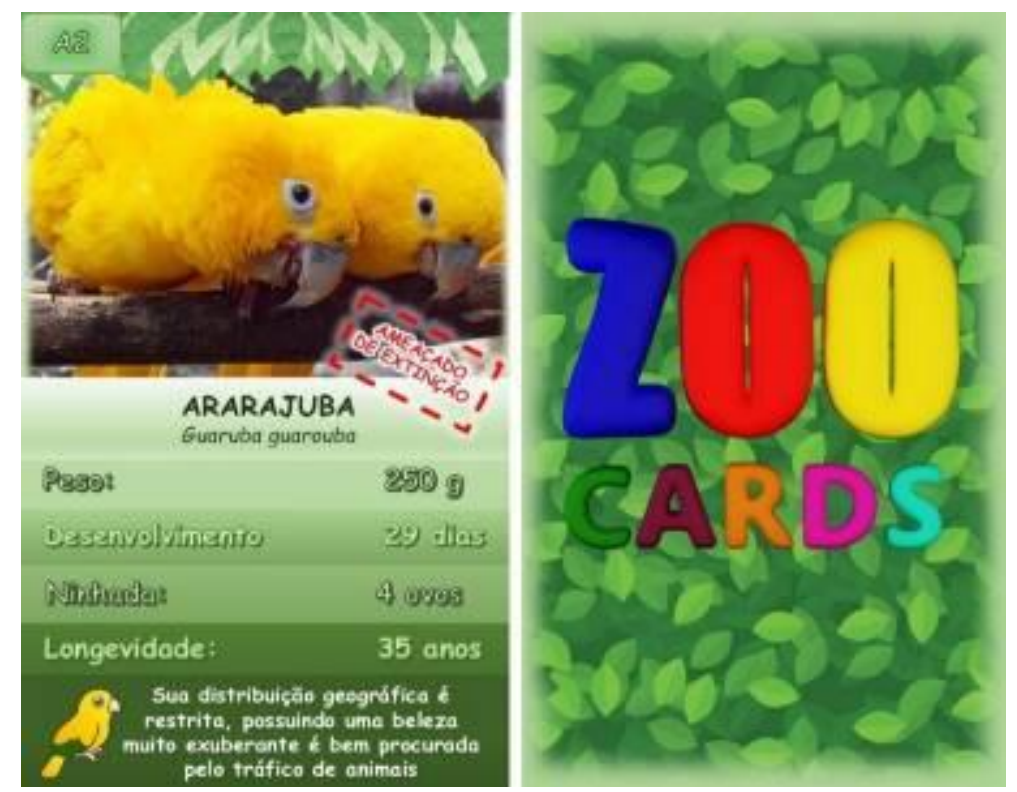

Figura 2: Exemplo de carta (frente e verso), em detalhes, do jogo "Zoo Cards". Fonte: Autoria própria. 
O jogo é composto também por uma carta com o selo "É o bicho" (Figura 3). O animal escolhido para representar esta carta foi o urubu-rei (Sarcoramphus papa), que é o primeiro dos urubus a se alimentar, pois consegue abrir a carcaça com seu bico robusto e, assim, considerado o "rei". A intenção é conscientizar as pessoas de que todos os animais são importantes na teia alimentar, independentemente de seus hábitos.

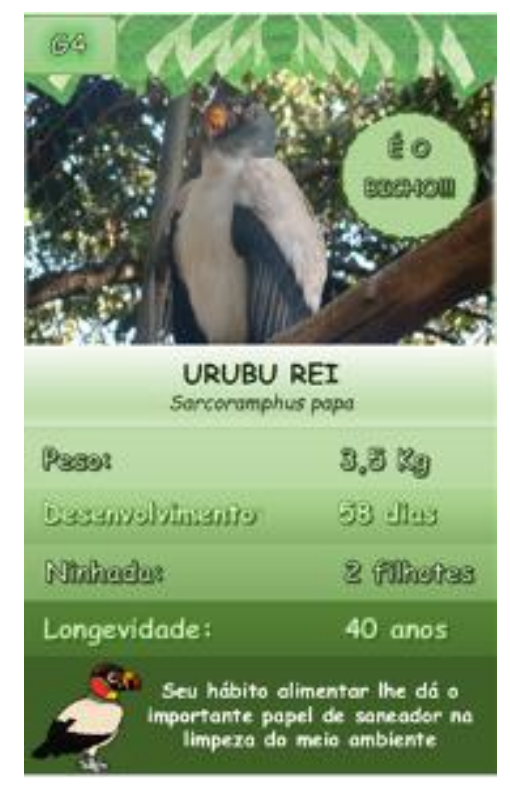

Figura 3: Carta "É o bicho" do jogo "Zoo Cards".

Fonte: Autoria própria.

Regras do jogo (opção 1): as cartas devem ser repartidas igualmente conforme o número de jogadores (dois a oito), e cada um deve ordená-las na sequência que preferir, mantendo o monte em sua mão de forma que possa ser vista apenas a primeira carta.

A rodada inicia com o jogador à esquerda de quem distribuiu as cartas. Ele deve escolher um dos itens para confrontamento (peso, desenvolvimento, ninhada ou longevidade) que julga ter o valor capaz de superar o mesmo item da carta de seus adversários, pronunciando-o em voz alta para os demais; estes anunciam então o valor da característica escolhida presente em suas cartas.

O jogador que apresentar a carta cujo item possui o maior valor leva todas as cartas da rodada e deve colocá-las na parte de trás do seu monte. $O$ jogo continua em sentido horário, com o próximo jogador escolhendo uma das características do animal da sua carta e anunciando-a aos demais. Assim se prosseguirá o jogo, até que um dos participantes fique com todas as cartas do baralho, vencendo a partida.

Em caso de empate, se a característica anunciada por um jogador tiver valor igual à mesma característica da carta de outro jogador, vence quem 
estiver com a carta que tem o selo "Ameaçado de extinção". Se ainda assim houver empate, o jogador da vez escolhe outra característica da mesma carta para desempatar a rodada. O jogador que tiver a carta "É o bicho" é capaz de vencer as demais cartas, menos àquelas cujo número no canto superior esquerdo é igual a 1, como por exemplo, A1, B1, C1, D1 etc.

Regras do jogo (opção 2): uma outra forma de se jogar é pela pontuação. As cartas devem ser repartidas igualmente conforme o número de jogadores (dois a oito). Visto que todas as cartas apresentam uma letra e um número no canto superior esquerdo ( $A 1, A 2, A 3$ ou $A 4$, por exemplo), estas só poderão ser baixadas quando um grupo de cartas estiver completo. Se o jogador tiver em mãos apenas a carta A3, ele deve "conquistar" as outras três para baixá-las na mesa (A1, $A 2$ e $A 4)$.

Na sua vez, o jogador pede para o próximo (no sentido horário) uma carta específica (a carta A2, por exemplo). Se ele possuir esta carta em mãos, deve obrigatoriamente ceder à carta ao jogador que a solicitou e, este por sua vez, continua a rodada; caso o participante não tenha a carta é possível pegar uma do monte, pois o objetivo é completar a sequência de letras e números (A1, A2, A3 e A4; B1, B2, B3 e B4 etc.).

O jogo continua com o próximo jogador solicitando uma carta específica ao outro, e assim sucessivamente. A partida termina quando qualquer participante (não necessariamente o que estiver jogando naquele momento) ficar sem nenhuma carta nas mãos, ou seja, que completar primeiro a sequência do(s) grupo(s) que lhe foi/foram distribuído(s). Ganha o jogador que baixar a maior quantidade de pontos na mesa, sendo que cada carta vale um ponto.

\section{O jogo didático como ferramenta de ensino no zoológico}

O jogo "Zoo Cards" foi disponibilizado aos visitantes do PEMA e, após observações, pôde ser considerado como um instrumento de ensino efetivo no zoológico, pois se percebeu $o$ envolvimento $e$ interesse dos participantes/jogadores, "aprendendo brincando" sobre os animais do PEMA, e estimulando o sentido investigativo e reflexivo. Espaços não formais de educação, como os zoológicos, têm grande influência no aprendizado e podem auxiliar no desenvolvimento do raciocínio científico no ensino de Ciências, e assim, atuar como espaço ativo de construção de atividades, principalmente em EA, visando à abordagem de questões ambientais (PIVELLI, 2006).

O fato de o jogo ser lúdico, divertido e prazeroso, o torna uma das formas mais eficazes de ensino, pois auxilia na construção de conhecimento e proporciona o crescimento e desenvolvimento intelectual, afetivo, social, criativo e motivacional (MIRANDA, 2001; SILVA; GRILLO, 2008). Quanto ao pensamento reflexivo, o jogo se mostrou eficiente ao promover a EA e, segundo Moratori (2003) e Silva e Grillo (2008), o jogo didático possibilita ao educando a participação do jogador no diagnóstico dos problemas ambientais e na busca de estratégias de resolução para os mesmos, estimulando a tomada Revbea, São Paulo, V. 13, № 4: 145-155, 2018. 
de consciência, bem como, uma conduta ética frente às questões ambientais com base em seu aprendizado durante a jogada.

É fundamental salientar que os jogos didáticos podem ser utilizados como auxiliares na construção do conhecimento em qualquer área de ensino (MARTINEZ; FUJIHARA; MARTINS, 2008), contudo não devem perder seu papel didático-pedagógico e se tornar um mero passatempo, uma atividade totalmente livre e descomprometida (CUNHA, 2012). Por combinar aspectos lúdicos aos cognitivos, entende-se que o jogo didático é um importante instrumento para trabalhar a EA na escola também, pois permite ao aluno tornar-se sujeito construtor de seu próprio conhecimento, promove a sensibilização em relação aos problemas ambientais, potencializando a mudança de atitudes e construção de valores ambientalmente corretos (SILVA, 2016). Partindo dessa premissa, o jogo "Zoo Cards" também pode ser utilizado no ambiente escolar, seja como instrumento para trabalhar a EA, como para revisar conteúdos já estudados ou para complementá-los.

\section{Considerações Finais}

Os zoológicos apresentam grande influência em conectar as pessoas com a natureza e são vitais para a construção do apoio à preservação. $O$ jogo didático desenvolvido, neste contexto, pode ser uma importante ferramenta para trabalhar a EA, despertando a sensibilidade e reflexão dos visitantes sobre a interferência do homem no meio ambiente e a necessidade de respeito à biodiversidade.

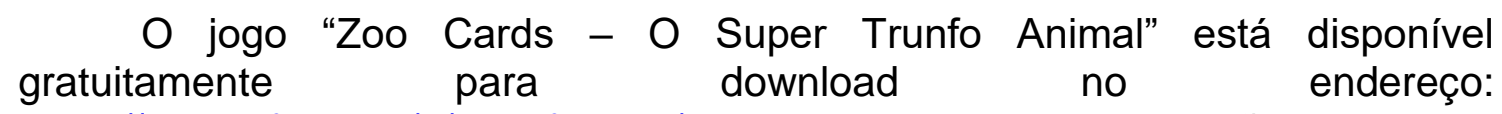
https://drive.ufscar.br/d/9508fe1c55/. Tanto o manual de instruções como as cartas já se encontram preparadas em formato pronto para a impressão, o que torna ainda mais fácil sua utilização como instrumento de ensino.

\section{Agradecimentos}

Os autores agradecem à Prefeitura Municipal e ao Parque Ecológico Municipal "Engenheiro Cid Almeida Franco" (PEMA), Americana, SP.

\section{Referências}

ARAGÃO, G.; KAZAMA, R. A função dos zoológicos nos dias atuais condiz com a percepção dos visitantes? Educação Ambiental em Ação, Novo Hamburgo, v.2, n.43, p.100-113, 2013.

BAILLIE, J.; HILTON-TAYLOR, C.; STUART, S.N. (Eds.). 2004 IUCN red list of threatened species: a global species assessment. Gland: IUCN, 2004. 191 p. Disponível em: <https://portals.iucn.org/library/sites/library/files/documents/RL2004-001.pdf>. Acesso em: 10 abr. 2018. 
BARONGI, R.; FISKEN, F.A.; PARKER, M.; GUSSET, M. (Eds.). Committing to conservation: the world zoo and aquarium conservation strategy. Gland, Switzerland: WAZA, 2015. Disponível em: <http://www.waza.org/files/ webcontent/1.public site/5.conservation/conservation strategies/committing to conservation/WAZA\%20Conservation\%20Strategy\%202015 Portrait.pdf>. Acesso em: 08 abr. 2018.

CMMAD. Comissão Mundial de Meio Ambiente e Desenvolvimento. Nosso futuro comum. Rio de Janeiro: Editora Fundação Getúlio Vargas, 1991.

CUNHA, M.B. Jogos no ensino de Química: considerações teóricas para sua utilização em sala de aula. Química Nova na Escola, v.34, n.2, p.92-98, 2012.

CUNHA, N.H.S. Brinquedo, desafio e descoberta. 1. ed. Rio de Janeiro: AE/MEC/RJ, 1998.

FORSHAW, J. Parrots of the World. Princeton: Princeton University Press, 2010. $336 \mathrm{p}$.

FRISCH, J.D.; FRISCH, C. D. Aves brasileiras e as plantas que as atraem. 3. ed. São Paulo: Editora Dalgas-Ecoltec - Ecologia Técnica, 2005. 476 p.

GODOY, T.A. de F.; OLIVEIRA, H.P. M. de; CODOGNOTO, L. Tabela periódica - um super trunfo para alunos do ensino fundamental e médio. Química Nova na Escola, v.32, n.1, p.22-25, 2010.

ICMBIO. Instituto Chico Mendes de Conservação da Biodiversidade. Portaria No 444, de 17 de dezembro de 2014. Brasília, 2014. Disponível em: $<$ http://www.icmbio.gov.br/cepsul/images/stories/legislacao/Portaria/2014/p mm a 4442014 lista esp\%C3\%A9cies ame\%C3\%A7adas extin\%C3\%A7\%C3\% A3o.pdf >. Acesso em: 10 out. 2017.

MACHADO, A.B.M.; DRUMMOND, G.M.; PAGLIA, A.P. (Eds.). Livro vermelho da fauna brasileira ameaçada de extinção. 1. ed. Brasília/Belo Horizonte: Fundação Biodiversitas, 2008. v. 2, 1420 p.

MARTINEZ, E.R.M.; FUJIHARA, R.T.; MARTINS, C. Show da Genética: um jogo interativo para o ensino de genética. Genética na Escola, v.3, n.2, p.2427, 2008.

MERGULHÃO, M.C.; VASAKI, B.M.G. Educando para a conservação da natureza: sugestões de atividades em educação ambiental. 2. ed. São Paulo: EDUC, 2002. $144 \mathrm{p}$.

MIRANDA, S. No fascínio do jogo, a alegria de aprender. Ciência Hoje, v.28, n.168, p.64-66, 2001.

MORATORI, P.B. Por que utilizar jogos educativos no processo de ensino aprendizagem? 2003. 28 f. Mestrado (Trabalho de Conclusão de Curso da disciplina de Introdução a Informática na Educação) - Universidade Federal do Rio de Janeiro, Rio de Janeiro, 2003. 
PIVELLI, S.R.P. Análise do potencial pedagógico de espaços não formais de ensino para o desenvolvimento da temática da biodiversidade e sua conservação. (Dissertação de Mestrado) - Faculdade de Educação, Universidade de São Paulo, São Paulo, 2006.

REIGOTA, M.A.S.; SANTOS, R.F. Responsabilidade social da gestão e uso dos recursos naturais: papel da educação no planejamento ambiental. In: PHILIPPI Jr., A.; PELICIONI, M.C.F. (Org.). Educação ambiental e Sustentabilidade. Barueri: Editora Manole, 2005, v. 3, p. 849-863.

SILVA, A.F. O jogo didático como instrumento para Educação Ambiental nas séries finais do Ensino Fundamental: proposta para trabalhar os temas Diversidade da Vida nos Ambientes e Diversidade dos Materiais. Revista Brasileira de Educação Ambiental (REVBEA), v.11, n.5, p.167-183, 2016.

SILVA, D.M.C.; GRILLO, M. A utilização de jogos educativos como instrumento de Educação Ambiental: o caso Reserva Ecológica de Gurjaú (PE). Contrapontos, v.8, n.2, p.229-238, 2008.

TELLES, M.Q.; DA ROCHA, M.B.; PEDROSO, M.L.; MACHADO, S.M.C. Vivências integradas com o meio ambiente. São Paulo: Sá Editora, 2002. $144 \mathrm{p}$.

TORRES, M.V.N.; BALASSIANO, L.K.A. Educação ambiental e princípio de sustentabilidade no mundo moderno. Revista Práxis, v.2, n.4, p.29-34, 2010.

TREVISOL, J.V. A educação em uma sociedade de risco: tarefas e desafios na construção da sustentabilidade. 1. ed. Joaçaba: Editora UNOESC, 2003. $166 \mathrm{p}$.

WAZA. World Association of Zoos and Aquariums. Construindo um futuro para a vida selvagem. Estratégia mundial dos zoos e aquários para a conservação, 2005. Disponível em: <http://www.szb.org.br/arquivos/wzacs.pdf>. Acesso em: 26 nov. 2017.

ZANON, D.A.V.; GUERREIRO, M.A.S.; OLIVEIRA, R.C. Jogo didático Ludo Químico para o ensino de nomenclatura dos compostos orgânicos: projeto, produção, aplicação e avaliação. Ciências \& Cognição, v.13, n.1, p.72-81, 2008. 